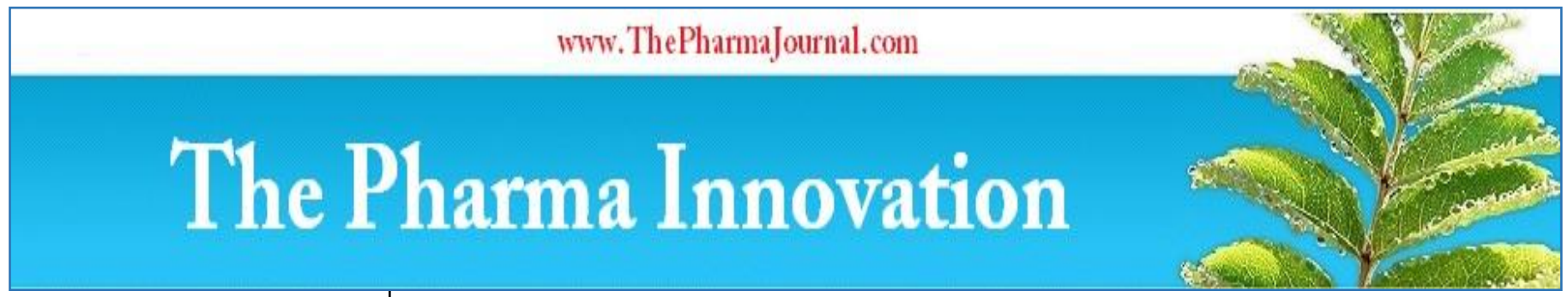

ISSN (E): 2277 - 7695

ISSN (P): 2349-8242

NAAS Rating: $\mathbf{5 . 2 3}$

TPI 2021; 10(4): 392-394

(C) $2021 \mathrm{TPI}$

www.thepharmajournal.com

Received: 16-02-2021

Accepted: 18-02-2021

\section{Neha Sharma}

Department of Animal

Nutrition, College of Veterinary

and Animal Science, Bikaner,

Rajasthan, India

Tribhuwan Sharma

Department of Animal

Nutrition, College of Veterinary

and Animal Science, Bikaner,

Rajasthan, India

\section{Jyoti Choudhary}

Department of Veterinary

Microbiology, College of

Veterinary and Animal Science,

Bikaner, Rajasthan University

of Veterinary and Animal

Sciences, Bikaner, Rajasthan,

India
Corresponding Author:

Neha Sharma

Department of Animal

Nutrition, College of Veterinary

and Animal Science, Bikaner,

Rajasthan, India

\section{Antimicrobial activity of some herbal feed additives}

\author{
Neha Sharma, Tribhuwan Sharma and Jyoti Choudhary
}

DOI: $\underline{\text { https://doi.org/10.22271/tpi.2021.v10.i4f.5964 }}$

\section{Abstract}

The present study was conducted to estimate in-vitro antimicrobial activity of six herbal plant extracts (Black pepper, Fennel, Turmeric, Black cumin, Ginger, Bay leaf) by using well diffusion method. It was determined that both methanolic and ethyl acetate extracts of these herbal additives possessed considerable antibacterial activity against Staphylococcus aureus, Pseudomonas aeruginosa, Proteus vulgaris, Salmonella typhi and Escherichia coli. The results suggested the potential use of Black pepper, Fennel, Turmeric, Black cumin, Ginger and Bay leaf as phytogenic growth promoter or feed additive in animals which can be further explored for better production.

Keywords: additive, antimicrobial, herbal, phytogenic

\section{Introduction}

Nowadays, use of feed additives in animal nutrition has gained prime importance and become obligatory as it improves feed efficiency and growth rate which generally results in lowering the production cost and better performance. Besides improving nutritive value of feed, feed additives tend to enhance animal performance with reduction in morbidity and mortality in birds. Being an eco-friendly alternative of antibiotics, natural growth promoter or phytogenic feed additives in poultry diet has received much attention in the recent years (Botsoglou et al., 2004) ${ }^{[5]}$ to enhance production and prevent disease conditions (Steiner and Syed, 2015). Phytogenic feed additives or natural feed additives comprised of a broad variety of substances, mainly extracts from plant materials, such as flowers, buds, seeds, leaves, twigs, bark, herbs, wood, fruits and roots (Burt, 2004) ${ }^{[6]}$. The active principles or bioactive constituents present in them have been responsible for a wide range of beneficial properties and physiological effects (Lee et al., 2004) ${ }^{[10]}$. Due to concerning drug resistance and residual effect problem associated with antibiotic growth promoters, these herbal plant extracts have been screened for their potential use as effective substitutes for the treatment of certain infections, improving animal performance and safe meat production for consumers.

Among various herbal extracts and essential oils being used in feed industry, some common indigenous herbs or spices are Black pepper, Fennel, Turmeric, Black cumin, Ginger and Bay leaf, respectively. In order to explore more regarding the use of these herbs, the aim of this present study is to estimate the antimicrobial properties of these natural feed additives which eventually allow the determination of its suitability as an alternative to antibiotic growth promoters in livestock and poultry production.

\section{Materials and Methods}

\section{Antibacterial activity}

The dried samples of Black pepper seeds, Fennel seeds, Turmeric rhizome, Black cumin seeds, Ginger rhizome, Bay leaf were ground and crude extract were prepared by Soxhlet extraction method using methanol. Five grams of powdered sample of these herbs were filled in thimble directly, was placed in Soxhlet apparatus, and extracted using ethyl acetate or methanol for 24 hrs or until the solvent in siphon tube of the extractor become colorless. The extracts were then concentrated in pre weighted vials on a rotary evaporator below $50^{\circ} \mathrm{C}$. Dried extracts were weighed and reconstituted with a known volume of solvent and were stored in vials at $4{ }^{\circ} \mathrm{C}$ for further experimental studies. Antibacterial activities of various herbal extracts were examined by the well diffusion method (Murray et al., 1995) ${ }^{[11]}$. The test organisms used are Staphylococcus aureus, Pseudomonas aeruginosa, Proteus vulgaris, Salmonella typhi and Escherichia coli. Stock cultures were maintained at $4{ }^{\circ} \mathrm{C}$ in nutrient broth. 
Active cultures for experiments were prepared by transferring a loopful of cells from the stock cultures to test tubes of nutrient broth for bacteria that were incubated without agitation for $24 \mathrm{~h}$ at $37{ }^{\circ} \mathrm{C}$. Media was prepared by dissolving $0.5 \%$ Peptone, $0.3 \%$ beef extract/yeast extract, $1.5 \%$ agar, $0.5 \% \mathrm{NaCl}$ in $100 \mathrm{ml}$ distilled water and autoclaved at $121{ }^{\circ} \mathrm{C}$ for $15 \mathrm{~min}$. Wells were prepared on agar plates to which 100 $\mu \mathrm{l}$ extract and solvent in control well was inoculated and the plates were kept for incubation at $37{ }^{\circ} \mathrm{C}$ for $24 \mathrm{~h}$. At the end of incubation, inhibition zones ( $\mathrm{mm}$ ) formed around the wells were measured with a transparent ruler.

\section{Results and Discussion}

In the present investigation, in vitro antibacterial activity of crude extract of six herbal extracts was qualitatively assessed based on the zone of inhibition. The zone of inhibition (Table 1) for methanolic extract of Black pepper was found to be comparatively more than others against various bacteria. Among five bacteria tested, Black pepper showed highest zone of inhibition against E.coli while lowest against $S$. typhi. In case of turmeric extract, relatively larger zone of inhibition (mm) was observed against S. aureus and E.coli as compared to others. For Black cumin, Fennel and Ginger, more antibacterial activity was seen against $S$. aureus while least was observed against $P$. vulgaris. No zone of inhibition was observed for Bay leaf methanolic extract against $P$. aeruginosa, $P$. vulgaris, $S$. typhi.

The ethyl acetate extracts of herbs in study showed relatively lesser antibacterial activity than methanolic extract against tested microorganisms (Table 2). The zone of inhibition varied from $9 \mathrm{~mm}$ (S. typhi) to $14 \mathrm{~mm}(S$. aureus) in case of Black pepper extract. The turmeric extract revealed no activity against $S$. typhi and $P$. vulgaris. Further, larger zone of inhibition was exhibited by Black cumin and Ginger extracts against $S$. aureus and by Fennel seed extract against E.coli. Also, the bay leaf extract demonstrated certain antibacterial activity against $S$. aureus, $P$. aeruginosa and E.coli. On comparing the antibacterial activity of above mentioned herbal extracts, Black pepper and Black cumin showed relatively more pronounced activity as compared to others.

The mechanism of action for various properties like antimicrobial activity of essential oils or herbs depends on their chemical composition and is not attributable to a single mechanism but a cascade of reactions involving the entire bacterial cell (Nazzaro et al., 2013) ${ }^{[12]}$. Further, it has been reported that the antimicrobial activity depends on the lipophilic character of the components which permeate the cell membranes and mitochondria of the microorganisms and hinder the membrane bound electron flow hampering energy metabolism of bacterial cell causing lysis of the cell membranes and denaturation of cytoplasmic proteins (Nazzaro et al., 2013) ${ }^{[12]}$.

The properties of herbs or spices or essential oils such as antibacterial, antifungal or anti-inflammatory varies from one plant to another in different regions which is attributed to many factors such as effect of climate, soil composition, age, stage, on the quality, quantity and composition of extracted product, different bacterial strains (Angioni, 2006) ${ }^{[3]}$. Also, type of solvent and method of extraction affect the quantity of essential oil and its extent of activity (Bedi, 2010) ${ }^{[4]}$.

The findings of present study collaborates well with those of Pundir and Jain (2010) ${ }^{[13]}$, Qadir et al. (2017) ${ }^{[1]}$, Algabri et al. (2018) ${ }^{[2]}$, Joe et al. (2009) ${ }^{[8]}$ and Kumar et al. (2019) who reported considerable antibacterial activity of herbal extracts or essential oils against various micro-organisms. Phenol, alcohols, ketones and aldehydes present in herbs are mainly associated with antibacterial actions. The presence of phytochemicals like sabinene, $\beta$-pinene, limonene, terpinene, borneol, carvone, carvacrol, 1, 8-cineol and linalool in Black pepper have contributed to its antimicrobial activity (Harold, 2004) ${ }^{[7]}$. Similarly, the active constituents exerting several beneficial properties to these herbs are present as zingiberol, zingiberine and bisabolene in Ginger, trans-anethole and estragole in Fennel, flavonoids, alkaloids, eugenol and linalool in Bay leaf, curcumins and other curcuminoids in Turmeric and p-cymene, carvacrol, thymohydroquinone in Black cumin, respectively.

It can be concluded that these herbal extracts possess appreciable antibacterial activity against tested organisms. Further, considering the safe meat production with no issue of drug residue and better animal performance, the herbal growth promoters could replace antibiotics in feed industry but these herbal products have numerous components and properties which need to be fully explored in order to get maximum benefits for optimum production.

Table 1: Antibacterial activity of methanol extracts of various herbal plants

\begin{tabular}{|c|c|c|c|c|c|c|}
\hline \multirow{2}{*}{ Microorganisms } & \multicolumn{7}{|c|}{ Zone of inhibition (mm) } \\
\cline { 2 - 7 } & Black pepper & Turmeric & Black cumin & Fennel & Ginger & Bay leaf \\
\hline S. aureus & 18 & 17 & 15 & 16 & 14 & 12 \\
\hline S. typhi & 13 & 7 & 12 & - & 8 & - \\
\hline P. aeruginosa & 15 & 11 & 13 & 11 & 10 & - \\
\hline P. vulgaris & 14 & - & 9 & 7 & - & - \\
\hline E. coli & 19 & 18 & 14 & 12 & 11 & 13 \\
\hline
\end{tabular}

Table 2: Antibacterial activity of ethyl acetate extracts of various herbal plants

\begin{tabular}{|c|c|c|c|c|c|c|}
\hline \multirow{2}{*}{ Microorganisms } & \multicolumn{7}{|c|}{ Zone of inhibition (mm) } \\
\cline { 2 - 7 } & Black pepper & Turmeric & Black cumin & Fennel & Ginger & Bay leaf \\
\hline S. aureus & 14 & 13 & 13 & 11 & 15 & 10 \\
\hline S. typhi & 9 & - & 10 & - & 9 & - \\
\hline P. aeruginosa & 12 & 10 & 11 & 12 & 9 & 8 \\
\hline P. vulgaris & 10 & - & - & - & - & - \\
\hline E. coli & 11 & 14 & 12 & 14 & 10 & 11 \\
\hline
\end{tabular}




\section{Acknowledgement}

Authors are thankful to College of Veterinary and Animal Science, Bikaner for providing all the facilities and fund to pursue this research study.

\section{References}

1. Abdul Qadir M, Shahzadi SK, Bashir A, Munir A, Shahzad S. Evaluation of phenolic compounds and antioxidant and antimicrobial activities of some common herbs. International journal of analytical chemistry 2017,

2. Algabri SO, Doro BM, Abadi AM, Shiba MA, Salem AH. Bay Leaves have Antimicrobial and Antioxidant Activities. Journal of Pathogen Research 2018, 1(1).

3. Angioni A, Barra A, Coroneo V, Dessi S, Cabras P. Chemical composition, seasonal variability, and antifungal activity of Lavandula stoechas L. ssp. Stoechas essential oils from stem/ leaves and flowers. Journal of Agricultural and Food Chemistry 2006;54:4364-4370.

4. Bedi N, Bedi PMS, Bodiwala HS, Singh IP, Bansal P. Scientific evaluation of an innovative herbal medicine for relief in respiratory disorders. Canadian journal of pure \& applied sciences 2010;4(3):1249-1255.

5. Botsoglou NA, Christaki E, Florou-Paneri P, Giannenas I, Papageorgiou G, Spais AB. The effect of a mixture of herbal essential oils or a-tocopheryl acetate on performance parameters and oxidation of body lipid in broilers. South African Journal of Animal Science 2004;34(1):52-61.

6. Burt S. Essential oils: Their antibacterial properties and potential applications in foods- a review. International journal of food microbiology 2004;94(3):223-253.

7. Harold M. Black pepper and relatives. On food cocking revised edition 2004, 427-429.

8. Joe MM, Jayachitra J, Vijayapriya M. Antimicrobial activity of some common spices against certain human pathogens. Journal of Medicinal Plants Research 2009;3(12):1134-1136.

9. Kumar M, Arya RS, Dhuria RK, Jain D, Nehra R, Sharma $\mathrm{T}$. In vitro antibacterial potentials of various extracts of ginger root powder and black cumin seed powder. Veterinary Practioner 2017;20(2):288-290.

10. Lee KW, Everts H, Kappert HJ, Van Der Kuilen J, Lemmens AG, Frehner M et al. Growth performance, intestinal viscosity, fat digestibility and plasma cholesterol in broiler chickens fed a rye-containing diet without or with essential oil components. International Journal of Poultry Science 2004;3(9):613-618.

11. Murray PR, Baron EJ, Pfaller MA, Tenover FC, Yolken HR. Manual of clinical microbiology, Washington DC 1995, 15-18.

12. Nazzaro F, Fratianni F, de Martino L, Coppola L, de Feo V. Effect of essentials oils on pathogenic bacteria. Pharmaceutic 2013;6:1451-1474.

13. Pundir RK, Jain P. Comparative studies on the antimicrobial activity of black pepper (Piper nigrum) and turmeric (Curcuma longa) extracts. International Journal of Applied Biology and Pharmaceutical Technology, 2010;1(2):492-500.

14. Steiner T, Syed B. Phytogenic feed additives in animal nutrition. In Medicinal and Aromatic Plants of the World 2015, 403-423. 